\title{
Sobre nova micose humana, causada por cogumelo ainda não descrito: Proteomyces infestans \\ pelos
}

\author{
Drs. ARTHUR MOSES e GASPAR VIANNA
}

Assistentes.

(Com as estampas 14 a 18 )

\section{Neue Mycose des Menschen, verursacht durch Proteomyces infestans, einen noch unbeschriebenen Pilz}

\author{
von \\ Drs. ARTHUR MOSES und GASPAR VIANNA \\ Assistenten.
}

(Mit Taf. 14 und 18)

Ás micoses até hoje rejistadas no homem contribuimos com um caso novo pelo seu quadro clinico e determinado por cogumelo cuja descrição não encontrámos na literatura.

Começamos pela historia clinica. Trata-se de um doente (B.S. L.), natural do Rio de Janeiro, de cor preta e de 18 anos de idade. Empregado de cocheira, ocupava-se diariamente em cuidar de cavalos.

No dia 18 de Fevereiro de 1911, procurou a Santa Casa de Misericordia e obteve entrada para o serviço clinico do Prof. FERNANDO TERRA, sendo nesta ocasião examinado pelo assistente da clinica dermatolojica, Dr. VICTOR TEIVE, a quem devemos a gentileza das presentes notas clinicas.

Nada informou o doente sobre antecedentes hereditarios ou pessoais.
$\mathrm{Zu}$ den bisher verzeichneten Mycosen des Menschen geben wir nachstehend einen neuen Beitrag in einem Krankheitsprozess, der nach seinem klinischen Bilde neu erscheint und dessen Erreger wir in der Litteratur nicht beschrieben fanden.

Mit dem klinischen Bilde zu beginnen, handelte es sich um einen 18-jaehrigen, in Rio geborenen Neger, der in seiner Stellung täglich mit Pferden umzugehen hatte.

Am 18-ten Februar 1911 suchte er den hiesigen allgemeinen Spital auf und wurde in der klinischen Abteilung von Prof. FERNANDO TERRA aufgenommen. Bei dieser Gelegenheit wurde er von Dr. VICTOR TEIVE, Assistenten der dermatologischen Klinik untersucht, dessen Guete wir nachstehende Notizen verdanken. 
Dificil era mesmo obter esclarecimentos sobre o estado morbido devido á confusão de ideas e á pouca facilidade que tinha o doente de falar.

Apenas conseguimos saber que era grande a fraqueza dos membros inferiores, forte a cefalea, acusando ainda o paciente máo estar geral.

Com dificuldade locomovia-se, simulando nesta ocasião a incoordenação motora dos tabidos.

A inspeção permetia o rejisto de grande numero de abcessos pequenos, endurecidos e fortemente aderentes ao tecido subjacente e localizados de preferencia nos membros superiores e inferiores.

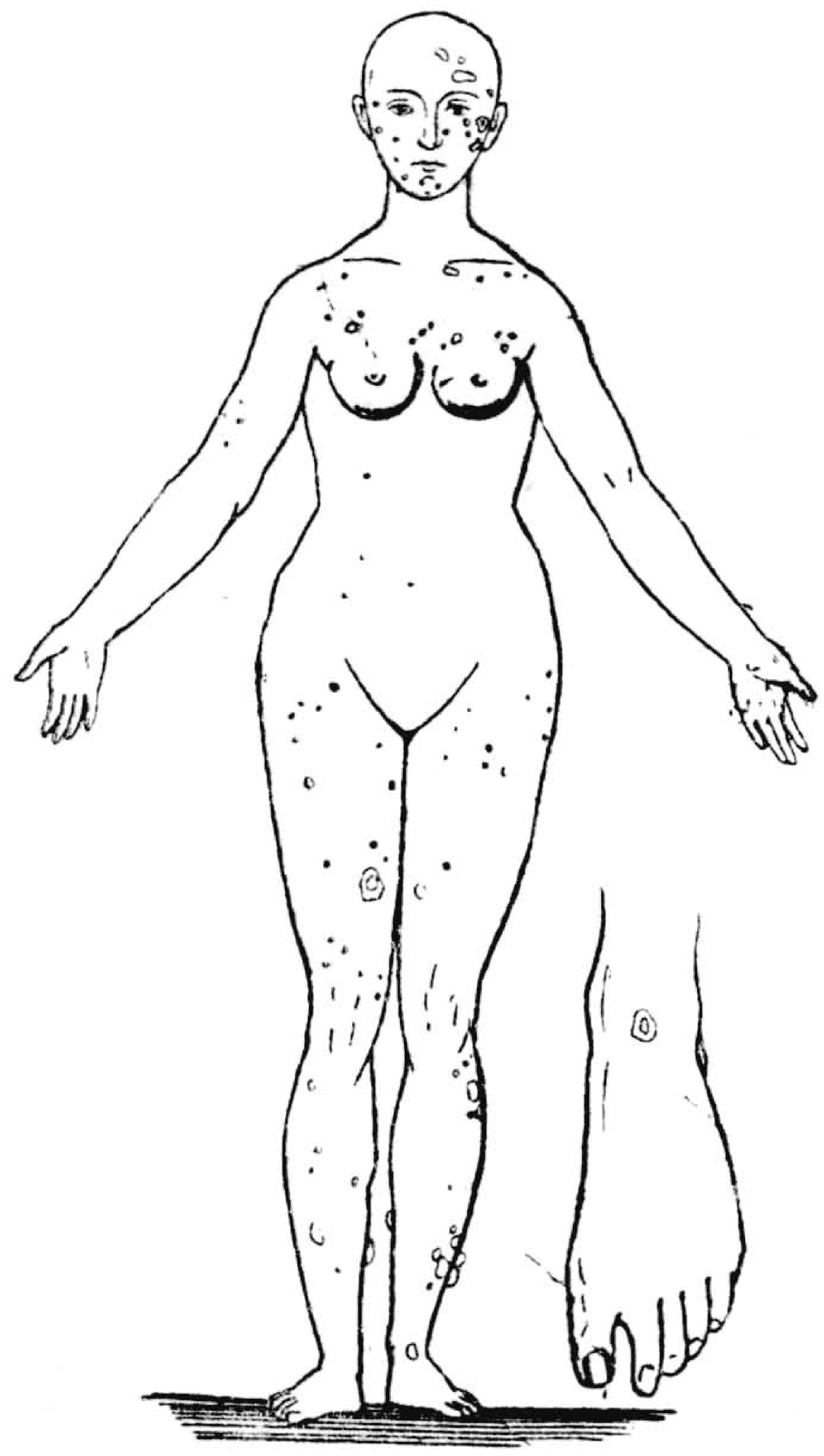

Fig. 1

A palpação indicava que havia tambem pontos de empastamento profundo, intensamente dolorosos. Havia alem disto numerosas flictenas.

Dos abcessos, diversos estavam abertos e deles saia liquido purulento, contendo sangue. Das flictenas, algumas facilmente se rompiam, deixando escapar liquido claro.
Ueber Heredität und persönliche Antezedentien gab der Patient keine Auskunft und selbst über den bestehenden Prozess war wegen bestehender geistiger Verwirrung und Schwierigkeiten bei Sprechen nur wenig Aufklärung zu erhalten. Doch wurde festgestellt dass grosse Schwæche der unteren Extremitäten, starker Kopfschmerz und allgemeines Übelbefinden verspürt wurde. Das Gehen war schwierig und erinnerte an die Koordinationsstörungen der Tabetiker.

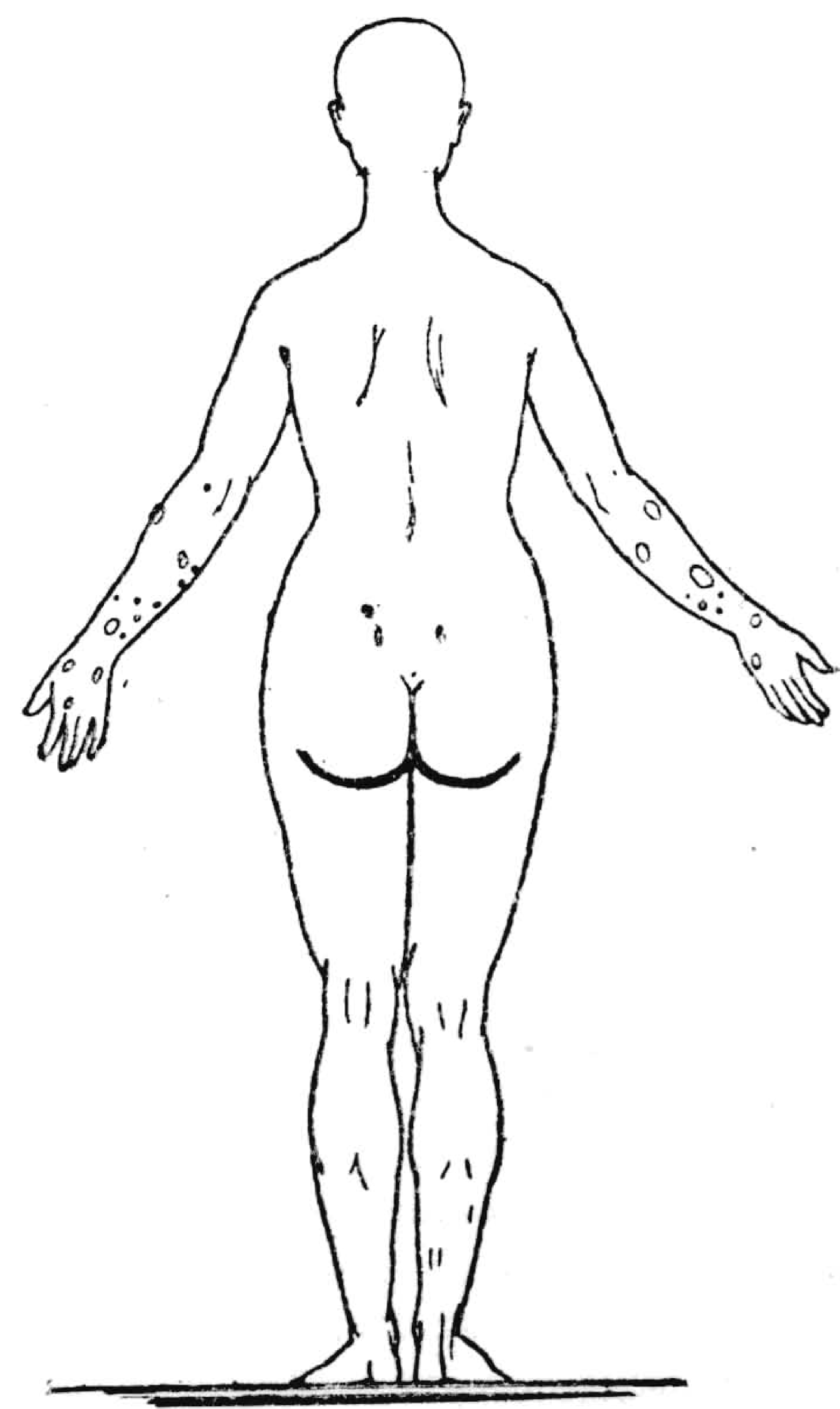

Fig. 2

Die Inspection liess besonders an den Extremitäten zahlreiche kleine Abszesse erkennen, welche sich hart anfühlten und dem unterliegenden Gewebe adhärierten. Durch die Palpation erkannte man auch tieferliegende, sehr schmerzhafte Infiltrationen. Ausserdem bestanden zahlreiche Phlyktänen. 
Muito edemaciados estavam os membros superiores e inferiores, principalmente os pés e as mãos, as quais nos ultimos dias de molestia já não era mais possivel fechar.

Dias apoz a entrada na enfermaria notavam-se no torax, face anterior e posterior, formação de pequenos abcessos semelhantes aos encontrados nos membros e de flictenas que predominavam na face (Fig. 1 e 2 do texto). Nos ultimos dias multiplicaram-se de modo extraordinario as lesões cutaneas e subcutaneas, aparecendo a face crivada de abcessos. Dada a ruptura expontanea das flictenas formavam-se dias depois crostas escuras.

Desde o dia em que se apresentou o doente no hospital esteve sempre em estado de subdelirio que ainda mais nos embaraçou a colheita de informações; a temperatura esteve sempre elevada, ocilando entre 39 e 400 .

O exame clinico acusou lingua saburrosa, forte timpanismo abdominal, acompanhado de constipação intestinal que só se manifestou dias antes da morte e abolição de respiração em alguns pontos, revelados pela asculta do pulmão.

Ás 3 horas da madrugada do dia 16 de Fevereiro faleceu o doente. Cinco horas apoz a morte reaiizou-se a autopsia da qual daremos sucinta nota.

Inspeção. Cadaver de homem adulto de côr preta, bem desenvolvido, com os membros superiores e inferiores fortemente edemaciados e com fenomenos pouco pronunciados de rijidez cadaverica. Dos orificios naturais liquido algum transudava.

Disseminados na superficie cutanea com predominio nos membros superiores e inferiores apresentava o cadaver vesiculas formadas por elevação da pele. A' menor abertura delas escapava liquido de côr amarela clara. Quando isolados o volume não excedia o de uma avelã: quando confluentes formavam extensa lesão sendo que a maior, do diametro de $6 \mathrm{~cm}$., estava localisado no hombro esquer-
Verschiedene Abszesse hatten sich geöffnet und liessen blu igen Eiter austreten, während sich aus einigen geplatzten Phlyktänen eine klare Flüssigkeit ergoss.

Die Extremitäten waren sehr ödematös, besonders die Füsse und Hände; letztere konnten während der letzten Tage der Krankheit nichtmehr geschlossen werden.

Einige Zeit nach der Aufnahme bemerkte man an Brusi-und Rückenseite des Thorax die Bildung von kleinen Abszessen, ähnlich denjenigen der Extremitäten und von Phlyktänen, die an der Brustseite zahlreicher waren. In den letzten Tagen nahmen die kutanen und subkutanen Herde ausserordentlich zu und das Gesicht erschien von Abszessen besät (Textfig. 1 u 2 ). Wenn die Phlyktänen spontan aufbrachen, bildeten sich nach einigen Tagen dunkle Krusten.

Vom Tage der Aufnahme an befand sich der Patient beständig in einem Zustande von Subdelirium, der die Aufnahme der Krankengeschichte noch mehr erschwerte; die Temperatur war immer ho $h$ und bewegte sich zwischen 39 und 400 .

Die Untersuchung ergab eine belegte Zunge, starken Meteorismus, begleitet von Verstopfung, welche erst einige Zeit vor dem Tode auftrat und bei der Auscultation der Thorax Unterdrückung der Atmungsgeräusche an einigen Stellen.

Patient starb am 16ten Februar, 3 Uhr Morgens. Fünf Stunden später fand die Autopsie statt, über welche wir kurz berichten.

Inspection: Gut entwickelte Leiche eines erwachsenen Mannes von schwarzer Hautfarbe. Leichenstarre gering. Die Extremitäten stark ödematös. Kein Erguss aus einer der natürlichen Körperöffnungen.

Über die Hautoberfläche zerstreut, aber besonders an den Extremitäten finden sich durch Abhebung der Haut entstandene Bläschen, aus denen bei der geringsten Verletzung hellgelbe Flüssigkeit aussickerte. Isolirt waren sie nicht über haselnussgross; beim Zusammenfliessen bildeten sie ausgedehnte Läsionen, von den die grösste mit einem Durchmesser von $6 \mathrm{~cm}$. an der rechten Schulter lokaiisiert 
do. Abertas estas extravasava-se o liquido, deixando descoberto tecido francamente inflamatorio. Nas mãos, principalmente na direita, eram muito pronunciadas estas lesões, ocupando quasi todo o dorso. Estendiam-se ainda sobre os dedos, principalmente o medio, onde havia foco purulento bastante profundo. Entretanto, mesmo ai não atinjia o tecido osseo.

Em pontos varios do corpo, sem predileção para este ou aquele, encontravam-se por palpação zonas endurecidas que se não desjocavam no tecido onde estavam situadas. O volume variava do de azeitona ao de ovo de galinha, alias raro e apenas percebido na parte infero-externa da perna esquerda.

Á propria inspeção ocular muitos delas se apresentavam sob a forma de saliencias mais ou menos claras.

Destes abcessos alguns, supraaponevro. ticos, se assentavam no tecido celulo-gorduroso, outras, subaponevroticos, situados principalmente nas pernas e nos braços, continham denso puz, não havendo entretanto a rejistar destruição notavel da massa muscular.

Nos musculos estriados encontravam-se focos purulentos, perfeitamente isolados ás vezes, em numero pequeno, outras, em numero elevado, como acontecia no deltoide esquerdo; sempre pouco volumosos, atinjiam, no maximo, a dimensão de ervilha.

Nos musculos profundos era total a ausencia de tais focos. É curioso assinalar a falta de correspondencia entre os focos intramusculares e os subaponevroticos. Coração normal. Pulmões de volume pouco aumentado e consistencia maior que a normal; a superficie coberta de pequenas granulações de côr clara, de volume de ervilha e, mais raramente, de outras maiores de volume de avelã.

Cortado o pulmão, granulações similares eram encontradas em toda superficie de seção, em numero relativamente menor que na parte periferica. Ganglios do mediastino de côr escura carregada, aumentados de volume.

Rins de volume aumentado, capsula fibrosa destacando-se cam certa dificuldade apresentam ao corte desenho de coloração war. Nach Eröffnung und Abfluss der Flüssigkeit erscheint eine stark entzündete Gewebsfläche. An den Händen, besonders an der rechten, waren die Veränderungen sehr ausgesprochen und nahmen die ganze Dorsalseite ein. Sie erstreckten sich über die Finger, besonders den Mittelfinger, wo ein ziemlich tiefer Eiterheerd vorlag, der aber auch hier nicht bis auf den Knochen reichte.

An verschiedenen Körperstellen, ohne Bevorzugung einer bestimmten Gegend, fühlte man Infiltrationen, welche sich innerhalb der Gewebsschichten nicht verschieben liessen. Ihre Volume schwankte von Oliven bis zu Hühnereigrösse; letztere war selten und wurde nur im unteren Teile der Aussenfläche des linken Beines beobachtet. Schon bei der Besichtigung traten viele derselben als mehr oder weniger deutliche Erhebungen hervor.

Von diesen Abszessen lagen einige über den Fascien im Paniculus adiposus; andere, besonders an Armen und Beinen, waren unter der Fascie gelegen, und enthielten dicken Eiter, doch war keine deutliche Zerstörung der Muskelmasse $\mathrm{zu}$ beebachten.

Ganz isoliert fanden sich in den quergestreiften Muskeln Eiterheerde, bald spärlich, bald in grosser Zahl, wie im linken Deltoides; sie waren sehr klein, höchstens erbsengross. In den tiefer liegenden Muskeln fehlten sie vollständig. Das Fehlen eines Zusammenhanges $z$ wischen subfascialen und intramus. kulären Heerden verdient hervorgehoben zu werden.

Herz normal. Lungen etwas volumöser und konsistenter wie gewöhnlich ; die Oberfläche besät mit kleinen hellen Granulationen von Erbsen-und seltener von Haselnussgrösse. Auf der Schnittfläche zeigen sich überall ãhnliche Granulationen, jedoch in geringerer Zahl, als an der Oberfläche. Mediastinaldrüsen sehr dunkel gefärbt und vergrössert.

Nieren vergrössert, die Kapsel nicht leicht abziehbar; auf der Schnittfläche eine helle gefärbte Zeichnung mit deutlichen Gefässen. Leber normal. Milz vergrössert, blutreich und mürbe. Nebennieren und Schilddrüsen ohne 
clara con vasos bem nitidos. Figado normal. Baço aumentado de volume, rico de sangue e muito friavel. Nada havia a rejistar nas capsulas suprarenais e na glandula tireoide. Ganglios inguinais de volume exagerado.

Cerebro com as meninjes pouco turvas, existindo na subaracnoide grande quantidade de liquido. Os vasos estavam fortemente distendidos pelo sangue. Aspeto das meninjes medulares identico ao das do cerebro.

De todos os organs, pontos lesados e abcessos foram retirados fragmentos e fixados em formol a $10 \%$ e liquido de ZENKER para ulterior exame histolojico. De dois abcessos foi colhido abundante material para ensaios de cultura.

Fizemos na mesma ocasião esfregaços de tecido, corando-os pelo metodo de GIEMSA e observámos bastonetes, na maior parte curtos, outras mais compridas, ás vezes dico. tomos (Est. 17 Fig. 2), constituidos por proto. plasma que se corava em azul claro, semeiado de granulações de cromatina que tomavam coloração vermelha intensa.

Bastante variavel é o numero destas granulações; ás vezes numerosas, outras não passam de duas, colocadas nos polos do bastonete.

Em continuação vemos ainda outras formas parasitarias, verificadas em cortes corados pela hematoxilina ferrea. Estas foram bem observadas nas capsulas suprarenais, onde existiam em numero grande e tambem no baço e pulmão.

Formadas, ás vezes, por uma granulação de cromatina, corada em negro pela hematoxilina e dispondo-se no extremo de uma parte protoplasmica clara (Est. 17 Fig. 5 e 7); outras vezes dividiam-se, o que se depreende da fig. 6 da mesma estampa, onde se encontram duas massas de cromatina intensamente coradas, bem separadas por um septo. Em estados mais adiantados de desenvolvimento vimos outras constituidas por segmentos diversos. São verdadeiras cadeias, onde se observam massas bem grandes de cromatina que podem ocupar toda extensão do segmento.

Pelo que posteriormente foi observado nos animais inoculados acreditamos que
Besonderheiten. Inguinaldrüsen ungewöhnlich gross.

Am Gehirn die Häute etwas getrübt, im Subarachnoidalraum reichliche Flüssigkeit. Gefässe mit Blut überfüllt. Die Rückenmark häute bieten dasselbe Bild wie diejenigen des Gehirnes.

Von allen Organen, sowie von den Läsionen und Abszessen wurden Stücke entnommen, welche zur histologischen Untersuchung in $10 \%$ Formol und ZENKER'scher Flüssigkeit fixiert wurden. Aus zwei Abszessen wurde reichliches Material für Kulturen entnommen.

Gleichzeitig wurden auch Ausstrichspräparate gemacht und nach GIEMSA gefärbt. Wir beobachteten in denselben Stäbchen, welche der Mehrzahl nach kurz, in der Minderzahl länger und manchmal gegabelt waren (Taf. 17, Fig. 2). Sie bestanden aus Protoplasma, welches sich hellblau färbte, und eingeschlossenen, intensiv rotgefärbten Chromatinkörnern. Die Zahl dieser Körner war ziemlich schwankend; manchmal beträchtlich, manchmal auf zwei beschränkt, welche sich an den Polen der Stäbchen befanden.

Ausserdem sind noch andere parasitäre Formen in mit Eisenhämotoxylin gefärbten Schnitten zu verzeichnen. Diese wurden deutlich in den Nebennieren beobachtet, wo sie sehr zahlreich waren; ausserdem in Milz und Lungen. Manchmal bestanden sie aus einem durch Hämatoxylinlösung schwarz gefärbten Chromatinkorn, am Ende einer hellen Protoplasmaportion gelegen (Taf. 17, Fig. $5 \& 7$ ); andere Male waren sie in Teilung, wie an Figur 6 ersichtlich, wo zwei stark gefärbte Chromatinmassen deutlich durch ein Septum getrennt erschienen. Auf einer weiteren Entwicklungsstufe sahen wir andere aus verschiedenen Segmenten bestehen. Sie bilden wirkliche Ketten, in denen man grosse Chromatinmassen sieht, welche die ganze Länge derselben erfüllen können. Nach späteren Beobachtungen an geimpiten Tieren glauben wir, dass die Teilung des Pilzes an den 
nestes pontos, onde se aglomera a cromatina, é que se processa a divisão do cogumelo.

Das formas observadas nos tecidos passemos para aquelas observadas no puz dos abcessos e que, de acordo com posteriores verificações em cultura e esfregaços de animais de experiencia, julgamos-nos autorisados a interpretar como formas de cultura. Corados pelo metodo de GIEMSA apresentam-se, nos esfregaços de puz, longos filamentos septados e corados em azul com pontos diversos de cromatina, esparsos.

Destes filamentos micelianos nacem brotos arredondados sem distribuição precisa, pontos de orijem de novo micelio que se dicotomiza dando ramos claviformes, o que nitidamente se vê na Est. 17 fig. 1.

Nesta mesma figura chamou nos atenção um ponto, onde existe reunião de formas isoladas, em que o protoplasma e cromatina são muito nitidos e que constituem provavelmente formas em evolução dos bastonetes anteriormente descritos.

Este modo de pensar é corroborado pelo exame das formas em cultura (Est. 16 Fig. $59,60,61)$ e em tecido de animal inoculado (Est. 17 Fig 33, 34, 35).

As figuras 3 e 4 da Est. 17 representam ainda esfregaços de puz do cadaver em que o desenho foi feito com ampliação maior, o que permitiu melhor verificar longos filamentos micelianos com septos mais proximos, limitando curtos segmentos, constituidos por protoplasma e cromatina bem evidenciados, estando alguns em via de divisão.

A principio a segmentação se faz no interior de membrana bem visivel, que só mais tarde acompanha a divisão, permitindo a separação de segmentos que, a nosso ver, nada mais são que aquelas formas, que em cultura constituem pontos de orijem de micelio. Anterior a esta segmentação, rejistámos, que o protoplasma em alguns pontos se estrangula para em seguida se dilatar.

Justamente nos pontos de estrangulamento processa-se a segmentação, que, terminada, permite que se isole o segmento no interior da membrana, que então se apresenta
Stellen stattfindet, wo sich das Chromatin anhäuft.

Von den im Gewebe beobachteten Formen gehen wir zu den im Abszesseiter beobachteten über. Nach späteren Untersuchungen von Kulturen und Ausstrichspräparaten von Versuchstieren halten wir uns für berechtigt, dieselben als Kulturformen zu erklären. Bei GIEMSAfärbung sieht man in den Ausstrichspräparaten lange septirte Fäden von blauer Farbe mit zerstreuten Chromatinpunkten.

Aus diesen Mycelfäden entspringen unregelmässig verteilte, rundliche Sprossen, aus denen ein neues Mycel hervorgeht, welches unter Zweiteilung keulenförmige Aeste bildet, welche man auf Taf. 17, in Fig. 1. deutlich erkennt. Ebendaselbst fällt ein Punkt auf, wo eine Ansammlung von isolierten Formen besteht, bei welchen Protoplasma und Chromatin deutlich hervortreten; wahrscheinlich bilden sie Entwicklungsformen der früher beschriebenen Stäbchen.

Diese Auffassungsweise wird durch die Untersuchung der Kulturformen ( Taf. 16, Fig. 59, 60 und 61) und solcher von geimpften Tieren (Taf. 17, Fig. 33-35) gestuitzt. Fig. $3 \& 4$ auf Taf. 17 zeigen noch Ausstriche von Eiter aus der Leiche, die bei stärkerer Vergrösserung gezeichnet wurden; man erkennt so deutlich lange Mycelfäden mit nahe zusammenstehenden Septen, welche kurze Teilstücken begrenzen, die deutlich aus Protoplasma und Chromatin bestehen und teilweise in Teilung begriffen sind.

Anfänglich erfolgt die Teilung im Innern einer deutlichen Membran, die erst später die Teilung begleitet und die Trennung von Segmenten gestattet, welche nach unserer Auffassung eben die Formen sind, welche in der Kultur die Ausgangspuukte des Myzels bilden. Vor dieser Teilung bemerken wir, dass sich das Protoplasma an einigen Stellen einschnürt, um sich nachher wieder auszudehnen. Gerade an diesen Einschnürungen findet die Segmentation statt, welche nach ihrer Vollendung gestattet, dass sich das Segment im Innern der Membran isoliert, welche dann besonders deutlich erscheint, da zwischen ihr und dem Protoplasma ein heller Zwischenraum 
muito mais nitida, havendo entre o protoplasma e a membrana um espaço claro. Facil é verificar este fato na figura 3 Est. 17 e nas formas individualisadas em muitos dos micelios da fig. 4. A fig. 25 Est. 16 indica claramente que ainda em cultura seguimos estes fatos.

$\mathrm{Na}$ fig. 4 dois fatos curiosos se salientam: a presença de celulas redondas limitadas por membranas, de onde parte micelio, o que ainda verificámos em rato inoculado e em cultura (Est. 16 Fig. 16), e a presença de micelio esteril, em que o protoplasma, inteiramente descorado, apresenta rara cromatina esparsa em finas granulações e outras muitas granulações que, pela reação corante, certamente não são de cromatina. Fato identico se verifica em cultura.

Descritas as formas verificadas no cadaver passemos áquelas rejistadas em animais inoculados com puz colhido na autopsia.

Salientemos que nunca em animal conseguimos reproduzir abcessos de marcha lenta semelhantes aos do doente, razão pela qual julgamos explicado, não termos verificado formas identicas ás descritas no puz humano.

As figuras numero 12 a 30 da Est. 17 referem-se todos a esfregaços de gomas no pulmão de ratos brancos inoculados com puz humano e corados pelo metodo de GIEMSA.

Do exame microscopico cuidadoso de esfregaços de organs diversos concluimos que só no pulmão deste animal se encontravam as formas micosicas que descreveremos. Alem deste nenhum outro germe foi observado.

A figura 12, Est. 17 representa uma forma isolada com protoplasma e nucleo central; a figura 13 nada mais é que a precedente que se divide e de 14 a 19 o germe crece, os nucleos se afastam e novamente se dividem dando logar ás figuras 20,21 e 22.

Divisões successivas de cromatina dão lugar á formação de filamentos semeiados de cromatina que se asemelham ao descrito no puz humano (Fig. 23, 24-25-26-27-29 Est. 17).

A figura 30 oferece $o$ caso interessante de filamentos que se segmentam nos pontos em que se divide a cromatina cuja distribuição nos permite concluir pela formação de e!e- besteht. Man kann dies leicht in Fig. 3 auf Taf. 17 konstatieren und für die individualisierten Formen bei vielen der Myzelien der Fig. 4. An Taf. 16, Fig. 25 geht deutlich hervo: dass wir diese Vorgänge auch in den Kulturen verfolgten.

In Fig. 4 fallen zwei eigentümliche $\mathrm{Er}$ scheinungen in die Augen: das Vorkommen runder, von einer Membran begrenzter Zellen, von welchen Myzel ausgeht (weiches wir auch bei geimpften Ratien und in Kulturen beobachteten) Taf. 16 Fig. 16 und dasjenige eines sterilen Myzeles, in welchem das ganz entfärbte Protoplasma wenig in feine Körnchen verteiltes Chromatin aufweist neben vielen anderen Körnern, welche nach der Färbungsreaktion zu schliessen, sicher kein Chromatin sind. Ein ähnliches Verhalten wird auch in der Kultur beobachtet.

Von der Beschreibung der Leiche festgestellten Formen gehen wir zu denjenigcn über, welche bei Tieren beobachtet wurden, welche mit dem bei der Autopsie gewonnenen Eiter geimpft wurden.

Wir heben hervor, dass es uns niemals gelang, beim Tiere langsamverlaufende Abszesse hervorzurufen, wie sie bei dem Kranken bestanden; aus diesem Grunde scheint es uns erklärlich, warum wir niemals Formen beobachteten, welche den aus menschlichem Eiter beschriebenen entsprachen.

Die Figuren 12-30 auf Tafel 17 beziehen sich alle auf Ausstriche von Knötchen aus den Lungen mit menschlichen Eiter geimpfter weisser Ratten, bei Anwendung der GIEMSAfärbung.

Aus der genauen Untersuchung von Ausstrichen der verschiedenen Organe schliessen wir, dass die von uns $\mathrm{zu}$ beschreibenden Pilzformen sich nur in den Lungen dieser Tiere vorfanden. Ausser diesen wurden keine anderen Keime gefunden.

Fig. 12 auf Tafel 17 zeigt eine isolierte Form mit Protoplasma und zentralem $\mathrm{Nu}$ cleus; 13 die vorhergehende in Teilung; von 14-19 wächst der Keim, die Kerne entfernen sich und teilen sich dann auf's neue, wie Fig. 20-22 zeigen. 
mentos isolados constituidos por protoplasma com duas granulações polares de cromatina como já acima foi descrito no puz humano. Da figura 28 depreende-se a existencia no rato de uma forma inicial da cultura.

Descrito o que observámos em tecidos e puz humano em exame microscopico direto diremos do resultado das culturas e das inoculações em animal de laboratorio do material colhido em autopsia.

Semeiado o puz nos meios habituais para isolamento de cogumelo, pois do quadro clinico nos tinha nacido a idea de se tratar de uma afeção micosica, estereis resultaram todas as culturas.

Inoculámos o puz colhido de abcessos superficiais e profundos em coelhos, cobaias e ratos brancos e cinzentos por via subcutanea, peritoneal e intraarticular.

Os coelhos morreram um mez depois, sendo que o primeiro, embora apresentasse no ponto de inoculação uma zona ulcerada rica em puz espesso foi despresado devido a contaminação por numerosos bacterios.

O segundo apresentava ao exame microscopico granulações pequenas no pulmão e nos esfregaços dos rins multiplas formas micosicas, algumas das quais em divisão.

As cobaias foram inoculadas nas articulações das extremidades posteriores com puz de cadaver, morrendo ambas vinte dias depois, apresentando nos pontos de inculação focos supurados e grande inflamação em todos os membros.

Outra cobaia com inoculação no peritoneo morreu, cerca de um mez depois.

A autopsia deste animal mostrou nas duas articulações dos membros posteriores e na de um membro anterior artrite purulenta e inflamação de todo o membro. No peritoneo grandes massas limitadas por espessas membranas, fortemente aderentes ao peritoneo constituidas por substancia caseosa de côr amarela suja e delas um aderia inteiramente ao figado.

O exame microscopico revelou a existencia de ce'ulas dejeneradas, detritos celulares
Sukzessive Chromatinteilungen führen zur Bildung von mit Chromatin besäten Fäden, welche den aus menschlichem Eiter beschriebenen gleichen (Taf. 17, Fig. 23-29).

Fig. 30 bildet den interessanten Fall von Fäden, welche sich an den Stellen segmentieren, wo sich das Chromatin teilt; seine Verteilung lässt uns auf die Bildung isolierter Elemente schliessen, welche aus Protoplasma mit zwei polaren Chromatinkörnern bestehen, wie sie schon oben aus menschlichem Eiter beschrieben wurden. Aus Fig. 28 kann man auf das Vorkommen einer initialen Kulturform bei der Ratte schliessen.

Nach Beschreibung dessen, was wir bei mikroskopischer Untersuchung des Eiters des Kranken beobachteten, wollen wir das Resultat der Kulturen und der mit dem bei der Sektion gewonnenem Materiale geimpften Laboratoriustiere besprechen.

Der Eiter wurde auf die gewöhnlichen zur Isolierung von Pilzen gebrauchten Medien geimpft, da das klinische Bild die Möglichkeit mykotischer Affektion nahe gelegt hatte; doch blieben alle Kulturen steril.

Wir verimpften den aus oberflächlichen und tiefliegenden Abszessen gewonnenen Eiter auf Kaninchen, Meerschweinchen, weisse und graue Ratten subcutan, intraperitoneal und intraarticulär.

Die Kaninchen starben nach einem Monat, doch wurde das erste wegen Verunreinigung durch zahlreiche Bakterien vorworfen, obwohl dasselhe an der Inokulationsstelle eine an dickem Eiter reiche geschwürige Zone zeigte.

Das zweite zeigte bei mikroskopischen Untersuchung kleine Granulationen in der Lunge und auf Ausstrichen der Nieren zahlreiche Pilzformen, von denen einige in Teilung begriffen waren.

Die Merschweinchen wurden mit dem Eiter aus der Leiche in die Gelenke der hinteren Extremitäten geimpft; beide starben nach zwanzig Tagen, wobei sie Eiterherde an dem Impfstellen und eine starke Ent zündung oder Extremitäten zeigten. Ein anderes, ins Peritoneum geimpftes, Meerschweinchen starb nach einem Monat. Die Sektion dieses Tieres zeigte an beiden Gelenken der 
e leucocitos, nada adiantando quanto á pesquisa etiolojica.

Retirámos deste material o suficiente para inocular coelho que morreu 15 dias depois, tendo o exame microscopico revelado muitas formas micosicas nos esfregaços de rim.

Em quatro ratos, dois brancos e dois cinzentos inoculámos puz do cadaver na articulação uns e no peritoneo outros. Os dois brancos morreram 32 dias depois e os outros cerca de 60 dias apoz a inoculação.

Todos apresentavam os pulmões inçados de focos purulentos miliares semelhante ao que se dá na esporotricose experimental, contendo puz viscoso que ao microscopio revelou formas identicas ás já observadas e descritas no puz humano.

Em esfregaços de pulmão, rim, figado e baço as formas acima mencionadas eram muito abundantes.

Foi semeiado em agar com maltose, de SABOURAUD, o material das gomas pulmonares, aparecendo as primeiras manifestações de cultura 20 dias depois.

Com o pulmão deste rato fizemos inoculação por via peritoneal em cobaia, coelho e ratos, morrendo os ultimos em dois dias, o que não permitiu tirar conclusões.

As cobaias apresentaram no peritoneo coleções purulentas, espessas e esverdeadas e os coelhos morreram 42 dias depois com formas micosicas, em esfregaços de pulmão e rim.

Daremos agora a descrição macroscopica da cultura que transplantada para agar com maltose de SABOURAUD em balão de ERLENMEYER, rapidamente se desenvolveu de modo a se ter em 24 horas impressão de crecimento vizivel. Em poucos dias (3-4) a cultura começa a tomar o aspeto que a carateriza.

De côr havana clara e aspeto cerebriforme, elevando-se suficientemente acima do nivel do meio de cultura, apresenta contorno redondo. (Est. 15 Fig. 4 ). hinteren und einem der vorderen Extremitäten purulente Arthritis und Entzündung des ganzen Gliedes, im Peritoneum ein grosses Exsudat welches aus einer käsigen Masse von schmutzig gelber Farbe bestand und von dicken, dem Peritoneum fest anhaftende Pseudomembranen begrenzt war. Eine derselben war ganz mit der Leber verklebt.

Die mikroskopische Untersuchung zeigte degenerierte Zellen, Detritus von solchen und Leukozyten, ohne für die Aetiologie etwas zu ergeben.

Mit diesem Materiale impften wir ein Kaninchen, welches 15 Täge später starb und bei der mikroskopischen Untersuchung zahlreiche Pilzformen in den Nieren zeigte.

Vier Ratten, zwei weisse und zwei graue, impften wir mit dem Eiter aus der Leiche, erstere intraperitoneal, letztere intraarticulär. Die weissen starben 32, die anderen ca. 60 Tage nach der Impfung.

Alle zeigten die Lungen von miliaren Eiterheerden durchsetzt, ähnlich wie bei der experimentellen Sporotrichose; der in denseIben enthaltene zähe Eiter zeigte unter dem Mikroskope ähnliche Formen, wie sie bereits im Eiter von der Leiche beobachtet und beschrieben wurden.

In Ausstrichen von Lungen, Nierér Leber und Milz fanden sich die oben erwähnten Formen sehr reichlich.

Material von Lungenknötchen wurde auf Maltoseagar nach SABOURAUD verimpft und nach 20 Tagen erschienen die ersten Anzeichen einer Kultur.

Mit Lunge von dieser Ratte impften wir Meerschweinchen Kaninchen und Ratten intraperitoneal; letztere starben schon nach zwei Tagen und waren daher nicht zum Studium verwendbar.

Die Meerschweinchen zeigten im Peritoneum dicke, grünliche Eiteransammlungen und die Kaninchen starben nach 42 Tagen mit Pilzformen in Lungen-und Nierenausstrichen.

Wir lassen hier die makroskopische Beschreibung der Kultur fo'gen. (Est.15 Fig. 4) Auf SABOURAUD'schen Maltoseagar in ERLENMEYER'schem Kölbchen übertragen, entwi- 
Posteriormente forma-se a zona periferica que se dispõe numa zona circular bem larga em que alternam numa disposição radiaria elevações e sulcos mais ou menos profundos. $\mathrm{Na}$ parte mais externa desta zona passa-se, sem solução de continuidade para outra mais lisa menos humida que insensivelmente termina no meio de cultura.

Em culturas antigas a zona periferica em primeiro logar cobre-se de enduto branco mais ou menos continuo, depois na parte central algumas das circumvoluções se apresentam pulverisadas de branco.

Nunca a cultura fica inteiramente branca como acontece na de Mastigocladium. Nem sempre as zonas central e perifericas são limitadas por duas linhas circulares concentricas, assim como ás vezes as circumvoluçôes da parte central podem ser bem mais elevadas.

A cultura acima descrita é a tipica. No mesmo meio porem outros aspetos se apresentam embora mais raramente. Descreveremos tres obtidos com mais frequencia no correr das transplantações.

Uma pouco se eleva acima do nivel do meio. Não apresenta zona periferica lisa com a distribuição de raios anteriormente falado, não tem contorno regular e termina mergulhando no meio de cultura. A côr é havana clara, às circumvoluções muito finas em numero maior e muito mais enoveladas. É raro encontrar se ponto esbranquiçado.

Outras vezes o aspeto é de uma seção de cone, cortado proximo a base, sendo que a face interior é constituida por circumvoluções dispostas de modo mais regular. A côr que é escura, aproxima-se da do chocolate e é mais esbranquiçado na periferia e pulverizada de pontos brancos no centro. A parte periferica no ponto onde se encontra com a superficie de seção apresenta pequena saliencia. A superficie de seção mais escura com circumvoluções mais iregulares apresenta-se fracamente pontilhada de branco. Destes ckeite sie sich rasch, so dass anscheinend schon nach 24 Stunden etwas Wachstum erkennbar war. In 3-4 Tagen beginnt die Kultur das charakteristische Aussehen zu zeigen. Sie hat einen runden Kontour, hellbraune Farbe, hirnartige Oberfläche und ist deutlich erhoben. Später bildet sich eine peripherische Zone, die breit ringförmig erscheint und in welcher radiär gestellte Erhebungen und Furchen von verschiedene Tiefe mit einander abwechseln. Nach aussen geht diese Zone kontinuirlich in eine glattere und weniger feuchte über, welche allmählich im Nährboden aufhört.

In alten Kulturen bedeckt sich zuerst die Peripherie mit einem weissen, mehr oder weniger zusammenhängenden, Belage; nachher erscheinen einige der Windungen im zentralen Teile weiss bestäubt. Niemals wird die Kultur ganz weiss, wie dies bei Mastigocladium der Fall ist. Die zentrale und die peripherische Zone sind nicht immer von zwei konzentrischen Kreisen begrenzt; auch können manchmal die Windungen in der zentralen Zone mehr erhoben sein.

Die soeben beschriebene Kultur ist typisch. Doch erscheinen auf demselben Nährboden, allerdings seltener, auch solche von anderem Aussehen. Wir werden drei beschreiben, welche im Verlaufe der Überimpfungen häufiger auftraten :

Eine derselben erhebt sich über den Nährboden und zeigt weder die erwähnte periphere glatte Zone mit der radiären Struktur, noch den regelmässiggen Kontour und endet indem sie in den Nährboden eindringt. Die Farbe ist hellbraun, die Windungen sind zahlreicher, feiner und komplizierter. Selten finden sich weissliche Punkte.

Andere erinnern in der Form an einen nahe der Basis gemachten Kegelschnitt, wobei der Kegelmantel aus regelmässige angeordneten Windungen besteht. Die dunkle, fast schokoladenbraune Farbe ist an der $\Gamma$ eripherie mehr weisslich und im Zentrum weiss bestaubt. Der peripherische Teil zeigt einen leichten Vorsprung, wo er mit der Oberfläche des Schnittes zusammentrifft. Diese ist dunkler mit unregelmässigeren $W$ indungen und 
dois, transplantando o germe, ora se obtem o mesmo tipo, ora o primitivo que tomámos por carateristico.

Outro aspeto mais curioso é o da Est. 15 Fig. 3 que consideramos de involução. Dela em transplantações successivas só se consegue o mesmo tipo sem nunca voltar ao primitivo. A cultura é côr castanha escura, muito humida, com as circomvoluções de dobras muito mais largas, limitando ás vezes, partes, da cultura de superficie lisa e de côr escura tocando ao negro.

Agar de SABOURAUD com glicoze. Cultura côr de creme muito elevada, contorno regular, circumvoluções numerosas e aproximadas. (Est. 15. Fig. 1).

Meio de conservação. - A cultura não se eleva acima do nivel do meio. A parte central, quasi inteiramente lisa, apresenta raros pontos que pouco se salientam e alguns sulcos que se dispoem como raios de circulo. A parte periferica estreita apresenta curtos sulcos por vezes muito proximos uns dos outros e que se dispoem ainda como raios, outras vezes os sulcos são muitos afastados e constituem continuação dos assinalados na parte central. Em parte da porção periferica ha a notar o aspeto branco que aparece tambem ainda em alguns pontos do centro. (Est. 15 Fig. 2).

Cenoura. - $\mathrm{O}$ meio é muito favoravel, obtendo-se em pouco tempo ricas culturas côr de creme com circumvoluções muito altas, bem largas e que rapidamente se cobrem de um enduto branco. Desenvolve-se bem na agua glicerinada no fundo dos tubos, formando uma espessa pele que pela ajitação se destaca. $O$ liquido ás vezes se turva, mas em geral mantem-se claro. (Est. 14. Fig. 2 e 3.)

Em batata, meio igualmente favoravel, o aspeto é identico, sendo de assinalar que se produzem em algumas das culturas elevações piliformes o que se observa bem na Est. 14 Fig. 1. No mais, a cultura é bastante semelhante á da cenoura, verificando-se ainda o mesmo aspeto na agua glicerinada. schwach weiss bestäübt. Überträgt man diess beiden Kulturen, so erhält man entweder denselben Typus oder den ursprünglichen, von uns als charakteristisch angesehenen.

Ein anderes, sehr sonderbares Bild, ist dasjenige von Fig. 3 Taf. 15, welche wir als Involution auffassen. Man erhält von diesen Kulturen bei weiterer Übertragung immer dasselbe Bild und der primitive Typus erscheint niemals wieder. Diese Kulturen sind dunkelbraun, sehr feucht, mit breiteren Windungen, welche manchmal Stellen umgeben, welche glatt und sehr dunkel, fast schwarz sind.

Auf Agar von SABOURAUD mit Glykose erscheint die Kultur rahmfarbig, sehr erhoben, mit regelmässigem Umriss und zahlreichen, dicht stehenden Windungen. (Est. 15. Fig. 1).

Auf dem Nährboden für die Konservierung ist die Kultur nicht erhoben; im nahezu ganz glatten zentralen Teile erscheinen wenige leicht erhobene Punkte und einige radiäre Furchen. Der schinale peripherische Teil zeigt kurze, manchmal dicht stehende und ebenfalls radiäre Furchen; andere Male sind die Furchen sehr entfernt und bilden eine Fortsetzung der im zentralen Teile beschriebenen. An einem Teile der peripherischen Zone bemerkt man ein weisses Aussehen, wie es auch an einigen Stellen im Zentrum erscheint. (Est. 15 Fig. 2).

Rüben bilden einen sehr günstigen Nährboden, auf welchem man in kurze Zeit üppige, rahmfarbene Kulturen erhält; die Windungen sind breit und hoch und bedecken sich rasch mit einem weissen Belag. Sie entwickelt sich gut im glyzerinhaltigen Wasser am Grunde der Röhrchen und bildet eine dicke Haut, welche sich beim Schütteln ablöst. Die Flüssigkeit trübt sich zuwe:len, bleibt aber gewöhnlich klar. (Est. 14. Fig. 1 u 3 ).

Auf Kartoffel, welche ein eben so guenstiges Nährmedium bilden, ist das Aussehen dasselbe, nur dass man bei einigen Kulturen das Aussehen von haarartigen Erhebungen bemerkt, wie Fig. 1, Taf 14, deutlich erkennen lässt. Der Nährboden ist demjenigen der Rüben übrigens sehr ähnlich und man beobachtet auch dasselbe Bild auf dem glyzerinhaitigen Wasser. 
Agar simples e agar de LOEFFLER Germinação abundante, côr de creme com a superficie rugosa e resistente.

Gelatina.-Germina na superficie, liquefazendo o meio.

Caldo maltosado. - $\mathrm{Na}$ superficie forma se pele muito espessa com abundantes circumvoluções largas e elevadas.

Caldo cenoura. - $O$ germe se cultiva bem neste meio, assim como na agua peptonada, formando na superficie pele que adere ás paredes dos tubos e que pela ajitação se desprende.

Abordemos agora á descrição microscopica da cultura. Oito horas de cultura em meio de SABOURAUD permitiu nos verificar formas iniciais de cultura que se reproduziam de modo analogo ao dos levedos o que nos foi permitido verificar em outras preparações de culturas mais antigas (Fig. 2, 22, 23, 24 e 28 Est. 16). Alem disso, conseguimos ainda verificar formação de micelio. Em geral o esporio torna-se piriforme com a cromatina disseminada como se vê da figura 3-9." Em outras f!guras 11,13 e 14 dispõe se a cromatina em faixa no ponto onde posteriormente se vae processar a divisão.

O conidio continua com pouca cromatina, alonga-se o micelio para depois se segmentar. Os segmentos estão sempre constituidos de protoplasma e cromatina (Fig. 18, 19, 26, 27). $\mathrm{Na}$ figura 25 , vêm-se no interior do filamento miceliano muitos conidios.

Posteriormente rompem-se os filamentos, dando saida aos conidios, como bem se verifica nas figuras $24,27,28$.

Dos conidios em liberdade nace o micelio, como nitidamente se observa na figura 28.

Da figura 29 a 52 Est. 16 estão representadas formas de culturas de quatro dias. Ao lado de conidios eliminados, encontram-se filamentos segmentados e alguns dos segmentos mais longos em via de ramificação. Alem destas, rejistamos ainda a presença de micelio esteril. (Fig. 47 e 52).

As figuras 53 a 59 são de cultura de seis dias. Ha a assinalar entre estas a presença de formas inteiramente analogas ás verificadas no tecido humano e de animais inoculados.
Auf einfachem Agar und solchem nach LOEFFLER erhält man üppige, rahmfarbige Kulturen mit runzeliger und resistente Oberfläche.

Auf Gelatine wächst der Pilz unter Verflüssigung.

Auf Bouillon mit Maltose bildet sich an der Oberfläche eine Haut mit breiten und hohen Windungen.

Auf Rüben dekokt wächst der Pilz gut, ebenso, wie in Peptonwasser, indem er an der Oberfiäche eine Haut, bildet, welche der Wand des Röhrchens anhaftet und sich beim Schütteln ablöst.

Wir wenden uns nun zur Beschreibung der Kulturen im mikroskopischen Präparate. Acht Stunden nach Übertragung auf den Nährboden von SABOURAUD konstatierten wir initiale Kulturformen, welche sich nach Art der Hefen vermehrten, wie wir es auch in anderen Präparaten von älteren Kulturen beobachteten (Taf. 16, Fig. 2, 22, 23, 24 \& 28). Ausscrdem konnten wir auch Myzelformen konstatieren. Gewöhnlich wird die Spore birnförmig mit zerstreutem Chromatin, wie Fig. 3-9 zeigen. Anderemale (Fig. 11, 13 \& 14) lagert sich das Chromatin in Bandform da, wo nachher die Teilung stattfindet.

In den Konidien bleibt das Chromatin spärlich; das Myzel streckt sich und teilt sich darauf. Die Teilstücke bestehen immer aus Protoplasma und Chromatin (Fig. 18, 19, 26827 ). In Figur 25 sieht man zahlreiche Konidien im Innern eines Myzelfadens.

Später zerreissen die Fäden und lassen die Konidien austreten, wie die Fig. 24, 27 \& 28 deutlich zeigen. Aus den frei gewordenen Konidien entwickeln sich die Myzelien, wie in Fig. 28 klar zu sehen ist.

In Fig. 29-52 der Taf. 16 sind Formen aus viertägigen Kulturen wiedergegeben. Es sind darunter Formen hervorzuheben, welche denen im menschlichen Gewebe und bei geimpften Tieren beobachteten vollständig entsprechen.

Die Fig. 59-61 stammen einer noch älteren Kultur von 15 Tagen und zeigen dieselben Formen, wie sie bereits von Nierenausstrichen von mit Kulturfiltrat geimpften Tieren beschrieben worden sind. 
As figuras $59,60,61$ são de cultura ainda mais antigas, de 15 dias e apresentam formas identicas áquelas já descritas em esfregaços de rim de rato inoculado com filtrado de cultura.

As demais figuras da estampa nada mais são que restos de cogumelo dejenerados e observados em cultura de 8 mezes.

A evolução do germe é extremamente rapida, a ponto de uma cultura de 8 horas oferecer esboçada toda evolução e em poucos dias (3-4) observarmos formas adiantadas de dejeneração.

Os desenhos da cultura foram todos realisados com obj. de $2 \mathrm{~mm}$. Ocul. comp. 3 e platina ao nivel da mesa de desenho.

Sobre a biolojia do cogumelo pouco adiantámos. Alem da liquefação da gelatina e coagulação do leite verificámos a não produção de indol, mesmo em culturas antigas, e a ausencia de fermentação em meios de cultura, contendo glicose lactose e manita.

Foi tambem verificada a resistencia ao calor, tendo sido notado que o aquecimento a 80 destruia o germe em uma hora, ao passo que apoz aquecimento de $1 / 2$ hora conseguia se não só culturá em meio artificial mas ainda infetar animais sensiveis.

$O$ que de mais curioso temos a rejistar é a filtrabilidade em velas BERKEFELD e CHAMBERLAND F.

Preparavamos para filtração fortes emulsões $\mathrm{e}$ inoculavamos quantidades grandes do filtrado por via peritoneal e em grande proporção dos animais inoculados conseguimos infeção.

Nunca do filtrado por mais larga que fosse a semeiadura, conseguimos cultura.

Estudada a cultura, digamos agora das inoculações.

Inoculámos pombos, galinhas, ratos, coelhos, cobaias e saguis. Com exceção dos dois primeiros que não contraiam a infeção todos os outros morriam em espaço variavel de tempo segundo a dose inoculada, tendo um sagui morrido 6 dias depois da inoculação.

Certo é que para se observar lesões comparaveis aos dos animais inoculados com
Die übrigen Figuren derselben Tafel zeigen nur Reste degenerierter Pilze, wie sie in einer acht Monate alten Kultur beobachtet wurden.

Die Entwicklung des Pilzes ist eine äusserst rasche, so dass schon eine achtstundige Kultur die Umrisse der Entwicklung zeigt und bereits nach 3-4 Tagen beobachteten wir vorgeschrittene Degenerationsformen.

Die Zeichnungen der Kulturen wurden alle mit einem Obj. von $2 \mathrm{~mm}$., Comp. oc. 3 auf der Höhe des Objekttisches gezeichnet.

Über die Biologie des Pilzes haben wir nicht viel festgestellt. Neben Verflüssigung der Gelatine und Gerinnung der Milch beobachteten wir das Fehlen von Indolbildung selbs in alten Kulturen, sowie der Gährung in Nährböden, welche Glykose und Mannit enthielten.

Es wurde auch die Resistenz gegen Hitzegrade geprüft und konstatiert, dass Erwärmen auf $80^{\circ}$ während einer Stunde den Pilzes tötete, während nach einer halben Stunde derselbe noch auf künstlichen Nährböden wuchs und empfängliche Tiere infizierte.

Als besonders merkwürdig müssen wir die Filtrabilität durch BERKEFELD filter und CHAMBERLAND'sche Kerzen (F) verzeichnen.

Für die Filtration bereiteten wir starke Emulsionen und verimpften grosse Quantitäten des Filtrates intraperitoneal und erhielten so die Infection eines grossen Teiles der geimpften Tiere.

Im zentrifugierten Filtrate fanden wir Pilzformen, doch gab uns dasselbe auch in reichlichster Aussat niemals Kulturen.

Nach Besprechung der Kulturen wenden wir uns zu den Tierversuchen.

Wir impften Tauben, Hühner, Ratten. Meerschweinchen, Kaninchen und Seidenäfchen. Die Vögel liessen sich nicht infizieren, aber die andern Tiere starben alle in verschiedenen Zeiträumen nach der Infektion, das eine Äffchen schon nach sechs Tagen.

Will man Veränderungen erziclen, wie sie denjenigen entsprechen, welche bei den 
material humano era necessario inocular dose muita pequena para que fosse lenta a evolução da infeção, como tivemos ocasião de observar em um rato, onde é fato curioso a pobreza de germes nos esfregaços.

Assim mesmo, deste material tão pobre pudemos isolar o germe cuja cultura era em tudo semelhante ao do isolado do rato inoculado com puz humano.

Alem das formas já descritas em animais inoculados com puz humano, nos inoculados com a cultura encontrámos ainda outras que convem salientar.

São entre estas, mais interessantes as verificadas em esfregaços de rim de rato branco inoculado com filtrado de cultura em vela CHAMBERLAND F. posteriormente aquecido a 80 o durante $1 / 2$ hora.

Desta figura torna-se clara a evolução do cogumelo o que aliás já foi descrito em cultura.

Dos conidios alguns ainda protejidos de membrana, tendo cromatina ás vezes em divisão (Est. 17 fig. 32, 33) nacem pequenos brotos, constituidos a principio exclusivamente por protoplasma (Est. 17 fig. $36,37,38$ ) possuindo depois um nucleo, como se observa nas figuras 39 e 40 da mesma estampa. Observa-se tambem que de outros conidios ainda não inteiramente libertados já começa a nacer micelio. (Fig. 48). Da figura 41 a 54 acompanha se a evolução do micelio até que terminada a segmentação se formam os elementos individualizados.

Pelo descrito facilmente se evidencia a dificuldade em colocar o cogumelo citado entre qualquer das especies já conhecidas.

Aproveitámos os ensinamentos de MATRUCHOT a proposito da classificação do genero Mastigocladium e colocámos o cogumelo entre as mucedineas hialosporas.

Consideramol-o asconiceto imperfeito que se aproxima do genero Mastigocladium e portanto dos generos Cephalosphorium e Verticillium. Propomos para ele novo genero e nova especie pela impossibilidade de identifical-o com qualquer dos cogumelos patojenicos descritos. mit menschlichen Material geimpften Tieren vorkamen, so muss man zweifellos sehr kleine Dosen einimpfen, damit die Infektion langsam verlaufe, wie wir Gelegenheit hatten bei einer Ratte zu beobachten, wo die Armut der Ausstrichpräparate an Pilzen ganz merkwürdig war. Dennoch konnten wir aus diesem so armen Materiale einen Pilz isolieren, dessen Kultur ganz derjenigen glich, welche von der mit menschlichem Eiter geimpften Ratte isoliert wurde.

Ausser den schon beschriebenen Formen bei mit menschlichem Eiter geimpften Tieren, fanden wir bei den mit Kultur geimpften noch andere, welche hervorgehoben $\mathrm{zu}$ werden verdienen. $\mathrm{Zu}$ den interessantesten gehören diejenigen in Ausstrichspräparaten aus den Nieren weisser Ratten, welche mit durch die CHAMBERLAND'sche Kerze geimpften und während einer halben Stunde auf $80^{\circ}$ erhitzten Kultures geimpft waren. Auf diese Weise kann man die Entwicklung des Pilzes, welche übrigens schon in den Kulturen beschrieben wurde, gut verfolgen.

Aus den Konidien, welche zum Teil noch von der Membran umgeben sind, zum Teil auch Chromatin in Teilung zeigen (Taf. 17, Fig. 32 \& 33) entstehen kleine Sprossen, welche ursprünglich nur aus Protoplasma bestehen (Taf. 17, Fig. 36-38), später aber einen Kern erhalten, wie Fig. $39 \& 40$ derselben Tafel zeigen. Man sieht, dass auch Myzel aus andern, noch nicht völlig frei gewordenen Konidien entspringt. In den Fig. 41-54 kann man die Entwicklung des Myzels bis zur Vollendung der Segmentierung und Bildung isolierter Formen verfolgen.

Aus der Beschreibung erkennt man die Schwierigkeit unseren Pilz bei einer der beschriebenen Arten unterzubringen. Gestützt auf die Lehren von MATRUCHOT über die Klassifikation des Genus Mastigocladium stellen wir den Pilz zu den Muzedineen mit hyalinen Sporen und taxieren ihn als imperfekten Askomyzeten, der dem Genus Mastigocladium und daher auch Cephalosporium und Verticiilium nahe steht. Da er sich weder mit diesen noch mit einem'der bekannten pathogenen Pilze identifizieren lässt, stellen 
Seguindo a proposição do Dr. ADOLPHO LUTZ, a quem muito agradecemos o interesse que tomou por nosso trabalho e os ensinamentos que nos ministrou, denominamos o novo cogumelo Proteomyces infestans, nome este que se explica pelas formas rudimentares de reprodução apresentadas e pela intensa ação patojenica observada.

Diremos agora o que observámos em exame histo-patolojico.

Os abcessos cutaneos, referidos na autopsia erão difusos e atinjindo o tecido celular subcutaneo. $\mathrm{Na}$ parte mais central existiam muitas celulas migradoras, principalmente polimorfonucleares, ao lado de detritos celulares. Viam-se aí raras formas micosicas, quasi sempre isoladas. A proporção que se aproxima da periferia encontram-se tecido conjuntivo e gordu oso, invadidos por muitas celulas fagocitarias cujo numero diminue até insensivelmente passar para o tecido são.

As celulas proprias do tecido sofrem ás vezes divisão, e não raro na parte periferica de alguns abcessos existem fibrohlastas em formação.

Na zona mais externa é intensa a vascularisação formada por vasos muito dilatados e completamente cheios de sangue, dos quais alguns sofreram rutura da parede de onde saiı sangue que se infiltrou até a parte central do abcesso. Entre as fibras dos nervos, invadidos pelos abcessos ha numero elevado de celulas inflamatorias.

Nos pontos, onde o abcesso não chega e não ha lesão do epitelio, este pode apresentar altura redusida, devido á compressão. Nos pontos onde a lesão se estende á epiderme, esta apresenta as celulas dissociadas por substancia liquida coagulada pelos fixadores. Esta dissociação é tanto mais notavel, quanto mais proximo se chega das camadas mais externas.

Os vasos das papilas estão fortemente distendidos por sangue. $\mathrm{O}$ tecido da papila wir für denselben ein neue Genus auf. Wir folgen einem Vorschlage von Dr. A. LUTZ welchem wir auch sein Interesse für unsere Arbeit und seine Belehrungen bestens verdanken, nennen wir den neuen Pilz: Proteomyces infestans, ein Name, der sich aus der Vielgestaltigkeit seiner Formen und der intensiven und progressiven pathogenen Eigenschaft erklärt.

Wir schliessen hier noch einige histopathologische Beobachtungen zu:

Die bei der Autopsie beobachteten Abszesse waren diffus und griffen auf das subkutane Bindegewebe über. In ihrem Zentrum fanden sich neben Zelldetritus Wanderzellen, besonders solche mit polymorphen Kernen. Man sah hier spärliche Pilzformen, die fast immer isoliert waren. Bei Annäherung an die Peripherie findet man Binde-und Fettgewebe von vielen Phagozyten erfüllt, deren Zahl allmählich abnimmt, während das Gewebe nach und nach normal wird.

Die Gewebszellen selbst gehen manchmal Teilungen ein und nicht selten beobachtet man an der Peripherie der Abszesse die Bildung von Fibroblasten. In der äussersten Zone ist die Vaskularisation sehr intensiv, die Blutgefässe sind sehr erweitert und mit Blut überfüllt; einige derselben sind geplatzt und lassen Blut austreten, welches den Abszess bis zu seiner Mitte infiltriert. Zwischen den Nerven, welche von den Abszessen erreicht wurden, finden sich entzündliche Zellen in grosser Zahl. Wo die Abszesse das Epithel nicht erreichen, kann dieses in Folge des Druckes in seiner Höhe stark reduziert erscheinen. Wo sich die Veränderungen auf die Epidermis erstrecken, sind die Zellen derselben durch eine Flüssigkeit getrennt, welche in Folge der Fixierung geronnen erscheint. Diese Anordnung wird um so deutlicher, je mehr man sich den äussersten Schichten nähert.

Die Blutgefässe der Papillen sind stark injiziert. Das Gewebe derselben ist mit Flüssigkeit durchtränkt, welche nach der Fixierung ein Fibrinnetz mit sehr dicken Balken zeigt. Hämorrhagien sind daselbst sehr häufig.

In den Muskeln, welche unter den subaponeurotischen Abszessen liegen, haben wir 
está infiltrado por liquido que, apoz fixação, apresenta uma rede de fibrina, de traves muito espessas.

Muito frequente é a hemorajia nas papilas.

Nos musculos, situados abaixo dos abcessos subaponevroticos, temos a assinalar a intensa reação inflamatoria no ponto correspondente á coleção purulenta e á destruição de varias fibras musculares. Nos musculos, onde se assestam lesões limitadas, o processo está perfeitamente circumscrito. Por vezes em plena massa muscular observa-se bem limitado foco supurado, formado pela destruição de fibras musculares, não se verificando reação inflamatoria ao redor do nodulo. Este contem na sua parte central restos de fibras musculares, leucocitos integros ou em destruição, celulas conjuntivas alteradas e raras hematias. Mergulhados neste tecido em destruição, encontra-se em muitos pontos capilares finos não destruidos. Na parte mais externa deles, vêm-se fibras musculares destruidas por celulas migradoras. Para fóra desta zona, o tecido não apresenta a menor alteração.

Dos organs descrevemos a capsula suprarenal, baço e pulmão que ao microscopio apresentavam lesões.

A capsula suprarenal estava profundamente alterada em todas as camadas.

As celulas perderam as conexões intimas e, em alguns pontos estavam completamente destacadas.

As celulas glandulares em todo o orgam coravam-se com dificuldade.

Principalmente na zona faciculada vêm-se numerosas formas micosicas, ora isoladas, ora dispostas em feixes. (Est. 18. Fig. 1.)

Baço: Raros pontos hemorajicos disseminados no parenquima e nestes pontos, ás vezes infiltrações lencocitarias. Raras formas micosicas, irregularmente dispostas.

Pulmão: Abcessos bem limitados no parenquima pulmonar e, ao redor deles, os alveolos cheios de exsudato fibrinoso, rico em celulas epiteliais e polinucleares. Em varios pontos dos tecidos pequenos focos de hepatisação vermelha.

No pulmão de animais de experiencia verifica-se bronco-pneumonia, pneumonia com einè intensive Entzündungsreak ion an den, der Eiteransammlung am Nächsten gelegenen, Stellen und den Untergang verschiedener Muskelfasern zu verzeichnen. Wo in den Muskeln gut begrenzte Eiterherde existieren, ist der Prozess scharf umschrieben. Manchmal beobachtet man in der Mitte der Muskelmasse einen scharf begrenzten Eiterherd, in welchem die Muskelfasern zerstört sind, während man um das Knötchen keine entzündliche Reaktion erkennt. Letzteres enthält im zentralen Teile Reste von Muskelfasern, veränderte Bindegewebszellen und spärliche rote Blutkörperchen, während mancherorts inmitten dieses zerstörten Gewebes feine Kapillaren erhalten sind. Ganz nach aussen sieht man durch Wanderzellen zerstörte Muskelfasern, während ausserhalb dieser Zone das Gewebe nicht die geringste Veränderung zeigt.

Die Nebennieren waren in allen Schichten stark verändert. Die dichte Verbindung der Zellen erscheint gestört und manchmal liegen dieselben vollständig frei. Die Drüsenzellen färben sich überall schwer. Besonders in der faszikulären Zone sieht man zahlreiche Pilzformen, bald isoliert, bald in Bündeln geordnet. (Taf. 18. Fig. 1.)

Im Milzparenchym findet man spärlich kleine Hämorrhagien, manchmal von leukozytären Infiltrationen begleitet, und unregelmässig verteilte Pilzelemente in geringer Zahl.

Die I ungen zeigen im Parenchym gut abgegrenzte Abszesse und um dieselben Alveolen, die mit einem, an Epithelien und polynukleären weissen Blutkörperchen reichen, fibrinösen Exsudate erfüllt sind. An verschiedenen Stellen finden sich kleine Herde mit roter Hepatisation.

In den Lungen von Versuchstieren konstatiert man Bronchopneumonie, rot oder grau hepatisierte Pneumonien, Knötchen und Abszesse. In solchen Veränderungen findet man die Parasiten immer in geringerer oder grösserer Zahl. In den Abszessen wird die an von Pilzfäden reiche Wandung von Leukozyten mit polymorphen Kernen und oft sehr zahlreichen Plasmozyten durchsetzt Eine andere merkwürdige Beobachtung ist auf 
hepatisação vermelha ou cinzenta, nodulos e abcessos. Nestas lesões sempre se encontra o parasito com maior ou menor frequencia. No abcesso, a parede cheia de filamentos micosicos, é invadida por celulas polimorfonucleares e plasmocitos, ás vezes muito abundantes.

Outro fato curioso se vê representado na Est. 18 Fig. 2, onde se observa a parede de um vaso arterial invadida pelo cogumelo. Observámos fato identico em paredes de bronquio.

Que seja o Proteomyces infestans o causador do quadro morbido observado, prova-se pelo resultado positivo da inoculação em rato, coelho e cobaia, pela ausencia de outro cogumelo ou de bacterio nos pontos lesados, pela cultura pura, obtida de animais inoculados, pelo quadro histo-patolojico e finalmente pelo reisolamento do cogumelo de animais inoculados com a cultura pura.

Trata-se pois de nova micose humana. Ao terminar, nossos agradecimentos ao Prof. FERNANDO TERRA que sempre nos permite a mais absoluta liberdade de trabalho no serviço clinico que dirije e ao $\mathrm{Dr}$. VICTOR TEIVE que muito nos auxiliou, fornecendo a observação do doente.

Manguinhos, Janeiro de 1913.
Taf. 18, Fig. 2, abgebildet, wo die Wand einer Arterie von den Pilzen befallen erscheint. Ähnliche Beobachtung machten wir auch an den Bronchien.

Die Gründe, welche dafür sprechen, dass das beobachtete Krankheitsbild durch den Proteomyces infestans hervorgerufen wird, sind folgende: Positives Resultat der Übertragung auf Ratten, Kaninchen und Meerschweinchen, Abwesenheit von anderen Pilzen oder Bakterien an den veränderten Stellen, Gewinnung von Reinkulturen von den geimpften Tieren, das histopathologische Bild und endlich die Wiedergewinnung des Pilzes aus den Geweben der mit Reinkulturen geimpften Tiere.

Es liegt also eine neue Mykose des Menschen vor.

Zum Schlusse sprechen wir Hrn Prof. TERRA, der uns in seiner Krankenabteilung stets völlige Arbeitsfreiheit gestattete, unseren besten Dank aus und ebenso Hrn. Dr. VICTOR TEIVE, der uns durch Mitteilung der Krankengeschichte einen wichtigen Beitrag lieferte.

Manguinhos-Rio de Janeiro, Januar 1913. 


\section{Explicação das estampas:}

Est. 14 - Fig. 1. Cultura em batata.

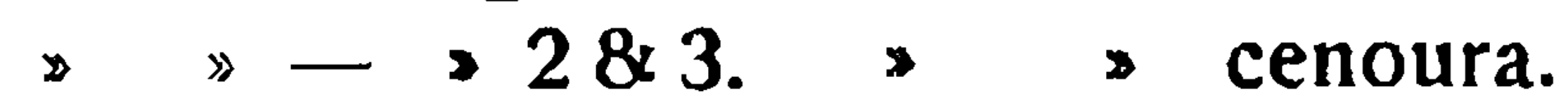

215- 1 . $>$ agar de SABOURAUD com glicose.

, -, 2 . Cultura em meio de conservação.

> - $>384$. Cultura em agar de SABOURAUD com maltose.

» 16 - Formas de culturas em diferentes estadios de evolução corádas pelo metodo de GIEMSA.

» 17 - Fig. 1-2-3 e 4. Preparações de puz de cadaver. Coloração pelo metodo de GIEMSA.

ఎ - 2-11 Formas micosicas encontradas em cortes de organs humanos. Coloração pela hematoxilina ferrea.

\ „ - 12-30 Esfregaços de gomas pulmonares de rato, córados pelo metodo de GIEMSA.

> - $>$ 31-54 Esfregaços de rim de rato branco inoculado com filtrado de cultura em vela CHAMBERLAND F. Coloração pelo metodo de GIEMSA.

- 18 - $\gg 1$. Capsula supra-renal invadida pelo cogumelo.

$\star \quad-\star 2$. Parede de vaso arterial invadido pelo cogumelo.

\section{Erklaerung der Abbildungen}

Taf. 14-Fig. 1. Kultur auf Kartoffel.

$>\gg->2 \& 3 \gg$ Rübe.

-15-»1. » $\quad$ Glykoseagar nach SABOURAUD.

- $\rightarrow$ 2. Kultur auf Conservirungsmedium.

», 384 Kultur auf Maltoseagar nach SABOURAUD.

- 16-Kulturformen verschiedener Entwicklung. GIEMSAfärbung.

* $\quad 17$-Fig. 1, 2, 3 \& 4: Präparate von Eiter aus der Leiche, nach GIEMSA gefärbt.

» menschlicher Organe gefunden wurden. Eisenhämatoxylinfärbung.

12-30: Ausstrichpräparate von Knötchen aus der Rattenlunge. GIEMSA.

> $-»$ 31-54:- Ausstrichpräparate aus der Niere einer mit durch CHAMBERLAND'sche Kerze (F.) filtrierten Kultur.

»18-»1. Von dem Pilz befallene Nebenniere.

2. Von dem Pilz befallene Arterienwand. 


\section{BIBILIOGRATIA.}

\section{Bibliographie.}

BLOCH, BR. UND VISCHER AD - 1911. Die Kladiose, eine durch einen bisher nicht bekannten Pilz (Mastigocladium) hervorgemfene - Dermatomykose.

Arch. I. Dermat $u$ Syphilis Bd 5 CVill H 3 Pg. 477-512. 


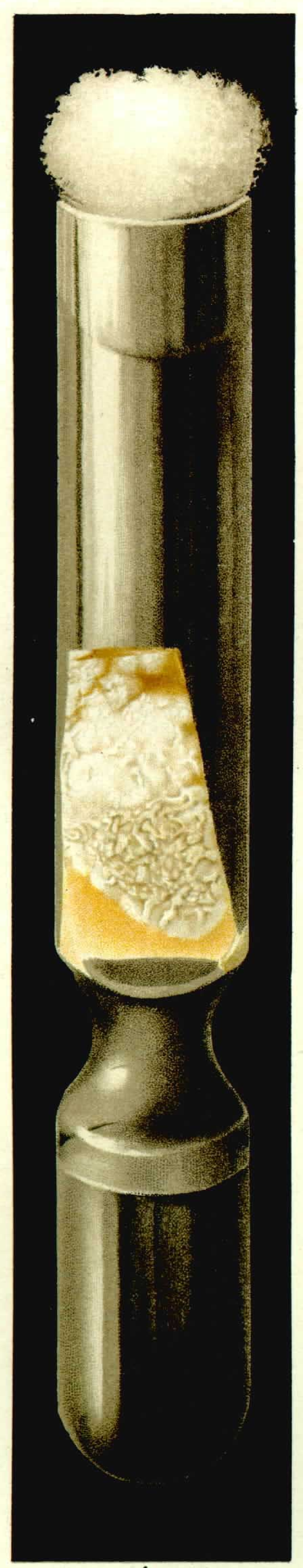

1

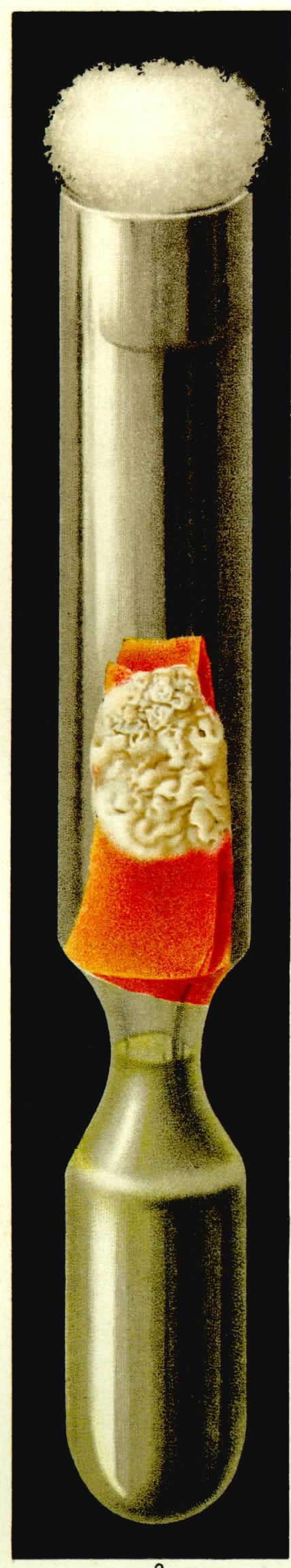

2

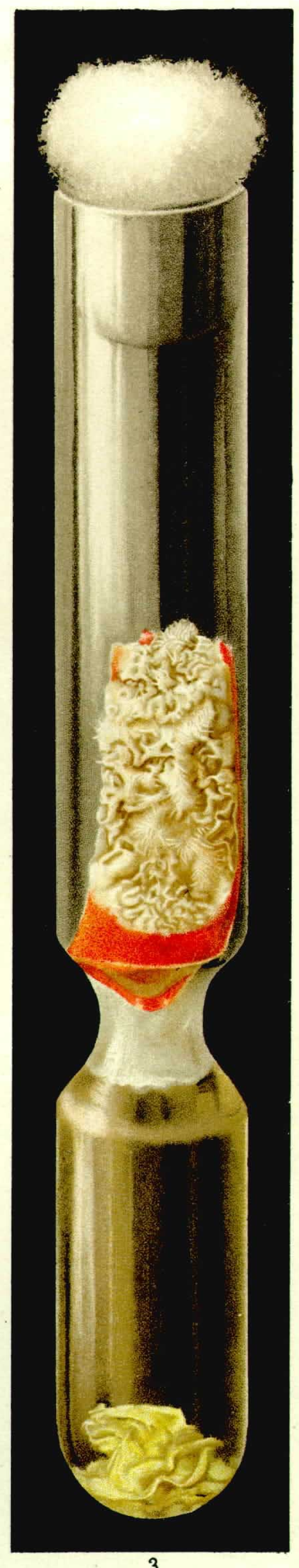

3 

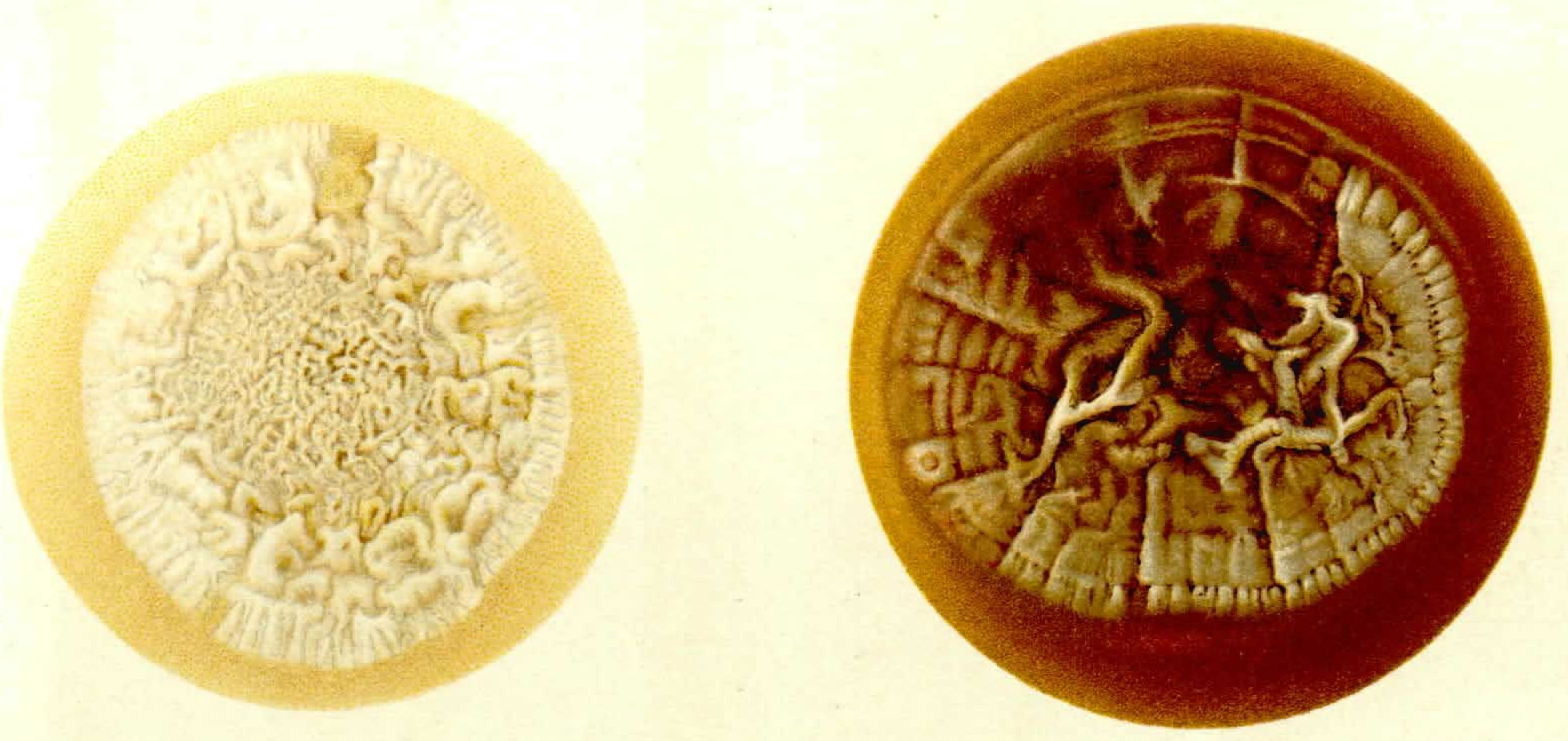

2
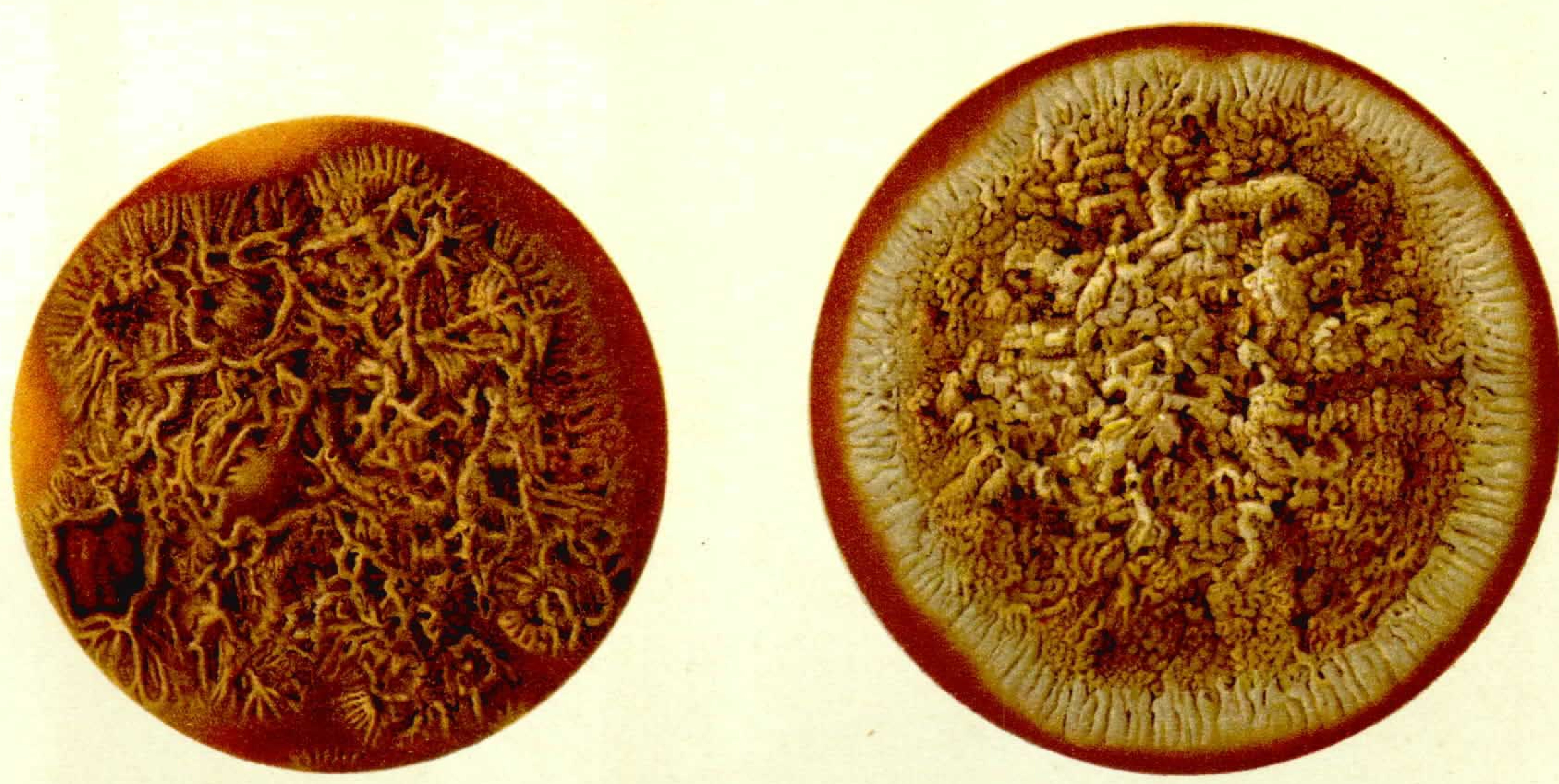

RUD. FISCHER, deL. 
$\div$ (1)

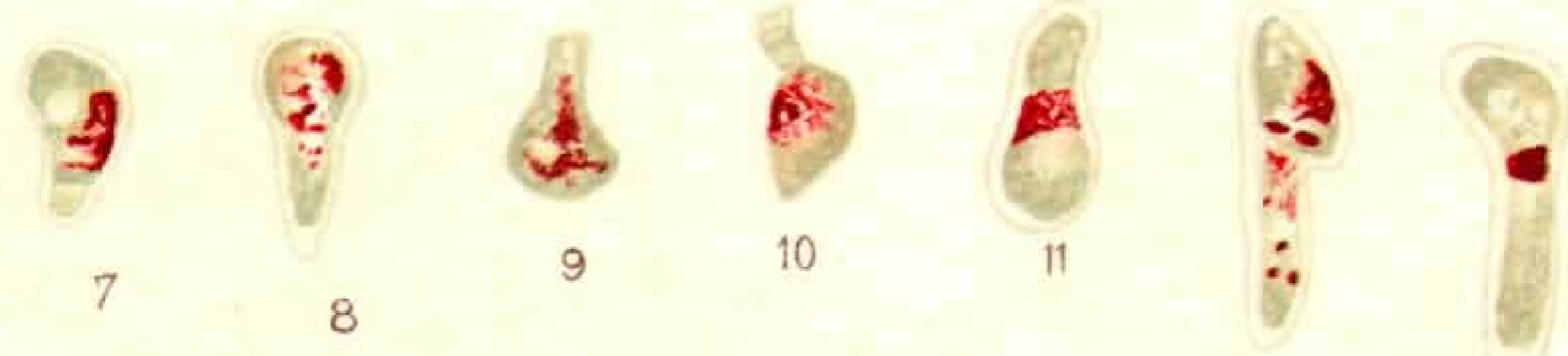
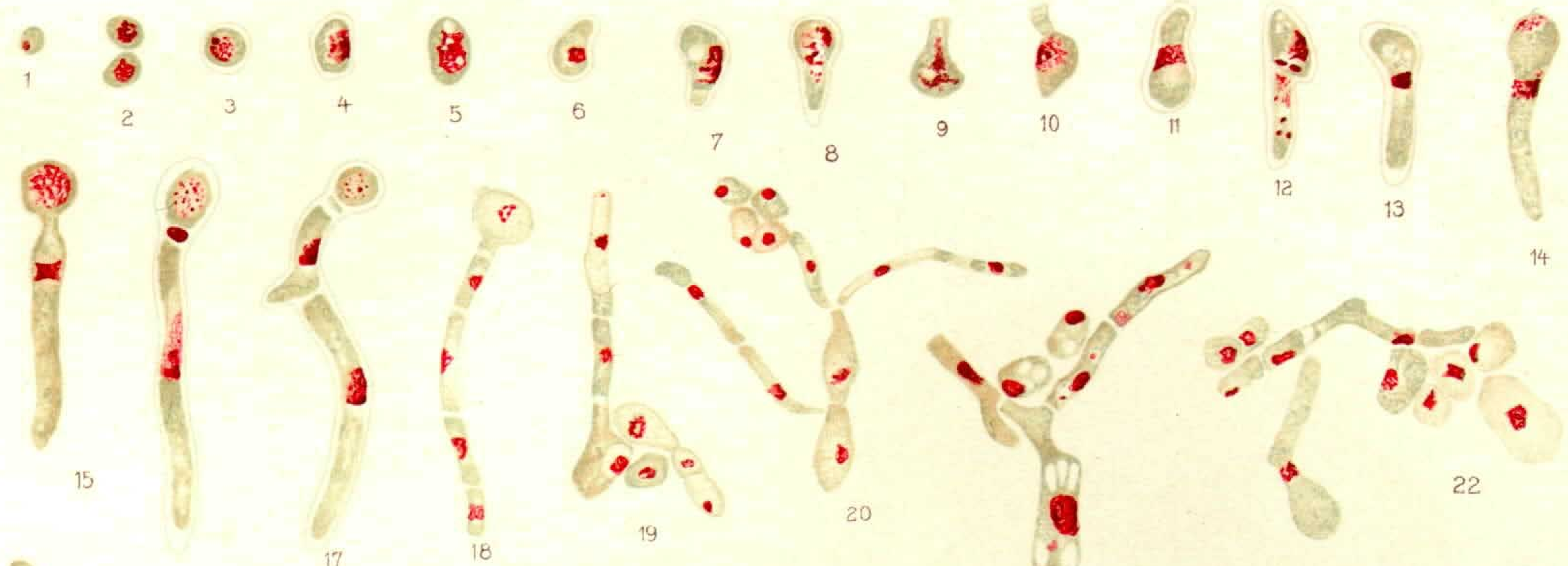

(3)

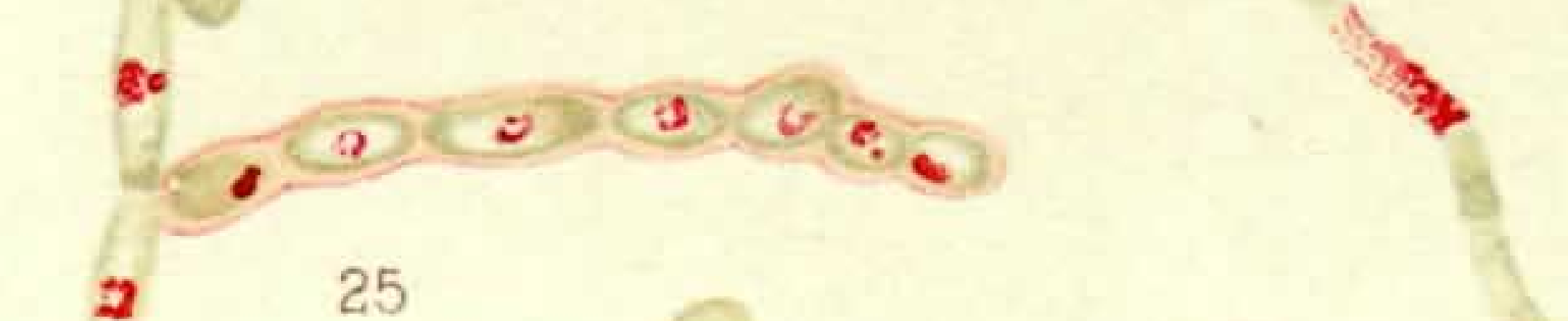

$\frac{\because}{3} \div:$
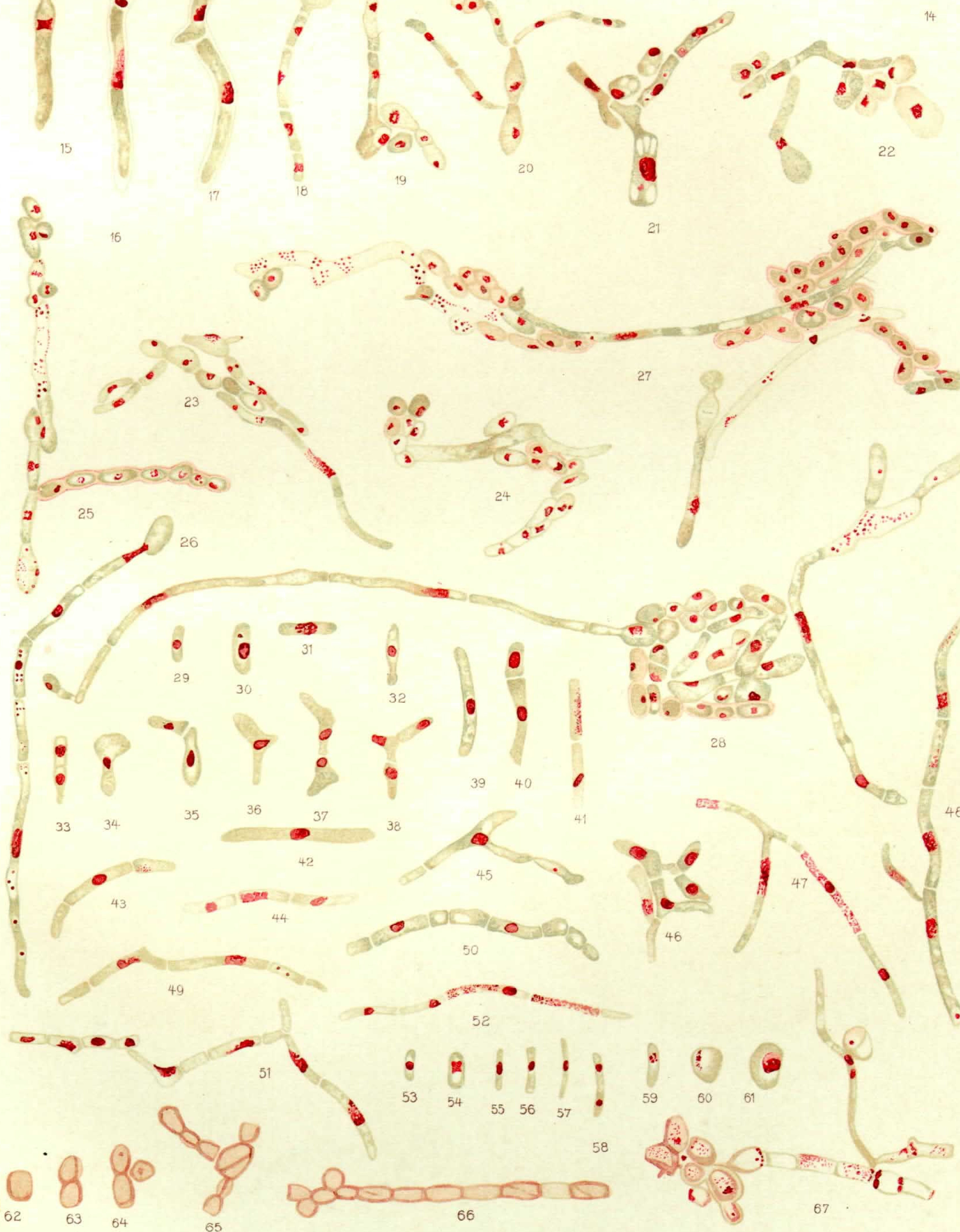

Castrosilva del. 

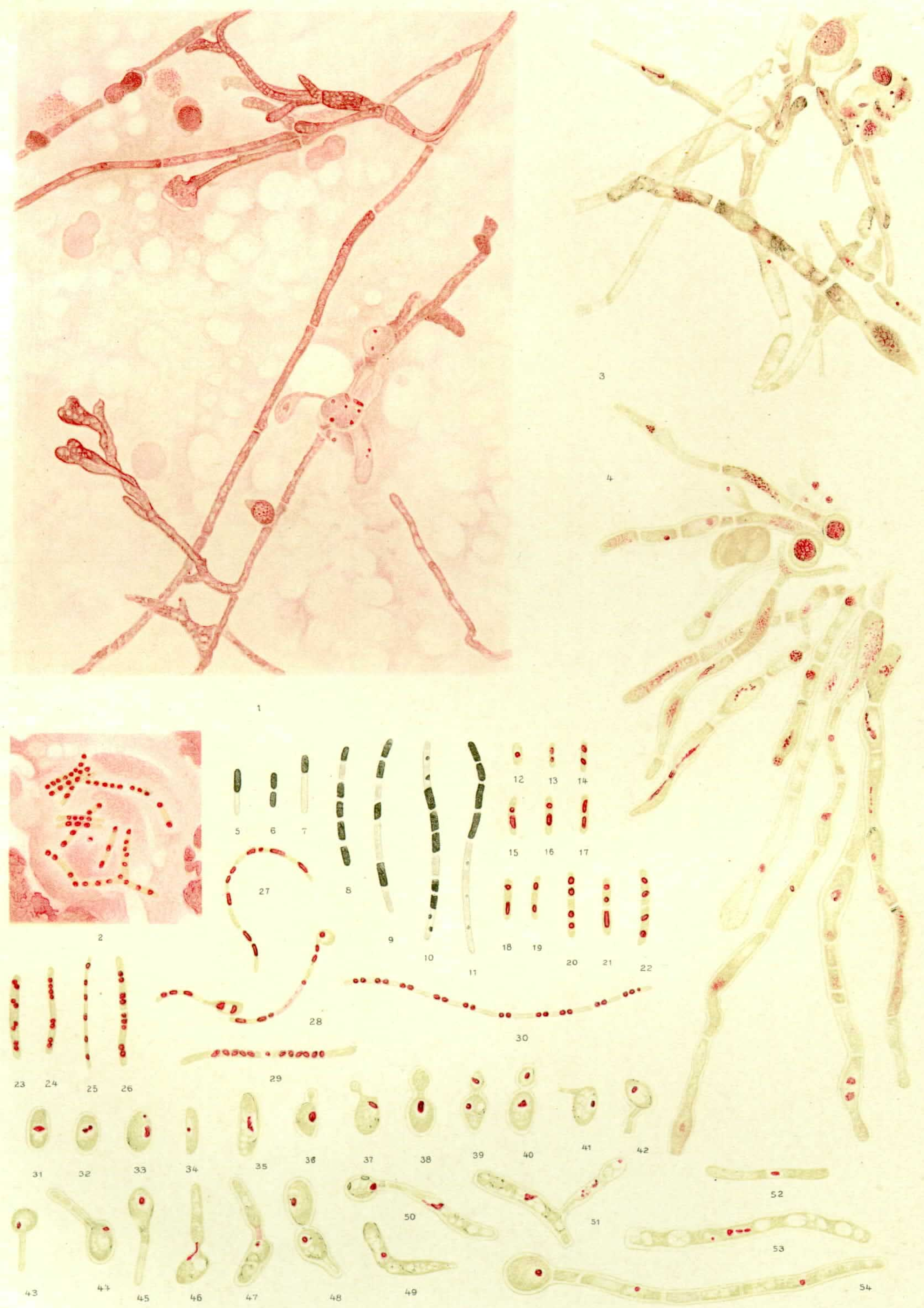

Castrosilva.del. 

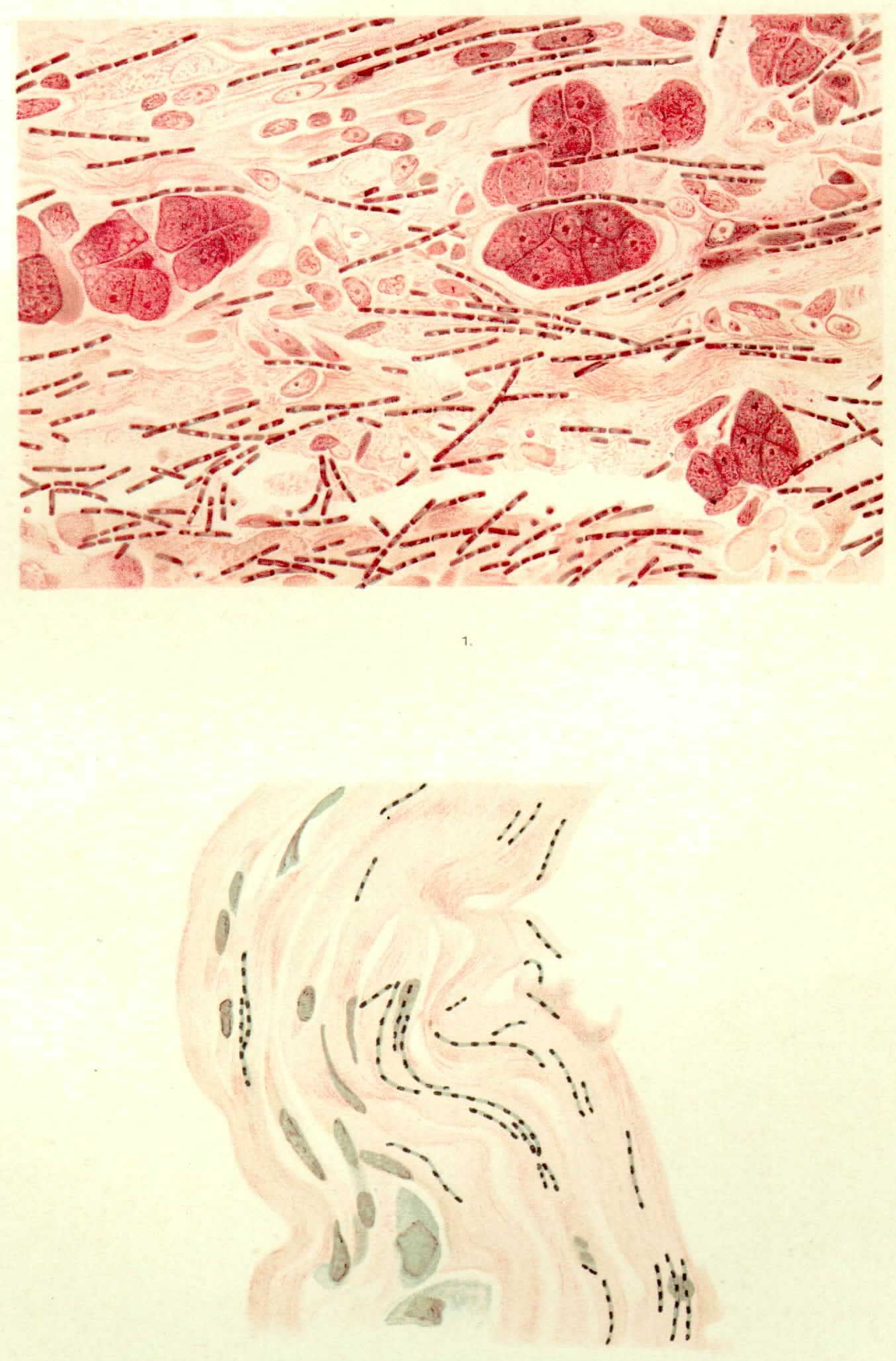

CastroSilva.del. 